Federal Reserve Bank of Minneapolis

Research Department Staff Report 393

July 2007

\title{
Money and Bonds: An Equivalence Theorem
}

\author{
Narayana R. Kocherlakota* \\ University of Minnesota, \\ Federal Reserve Bank of Minneapolis, \\ and NBER
}

\begin{abstract}
This paper considers four models in which immortal agents face idiosyncratic shocks and trade only a single risk-free asset over time. The four models specify this single asset to be private bonds, public bonds, public money, or private money respectively. I prove that, given an equilibrium in one of these economies, it is possible to pick the exogenous elements in the other three economies so that there is an outcome-equivalent equilibrium in each of them. (The term "exogenous variables" refers to the limits on private issue of money or bonds, or the supplies of publicly issued bonds or money.)
\end{abstract}

*I thank Shouyong Shi and Neil Wallace for great conversations about this paper; I thank Ed Nosal, Chris Phelan, Adam Slawski, Hakki Yazici and participants in SED 2007 session 44 for their comments. I acknowledge the support of NSF 06-06695. The views expressed herein are mine and not necessarily those of the Federal Reserve Bank of Minneapolis or the Federal Reserve System. 


\section{Introduction}

In this paper, I examine four different models of asset trade. In all of them, immortal agents face idiosyncratic shocks to tastes and/or productivities. They can trade a single risk-free asset over time. Preferences and risks are the same in all four models. The models differ in their specification of what this single asset is.

In the first two models, agents trade interest-bearing bonds. In the first model, agents can trade one period risk-free bonds available in zero net supply, subject to personindependent borrowing restrictions. In the second model, agents can trade one period risk-free bonds available in positive net supply, but they cannot short-sell the asset. A government pays the interest on these bonds, and regulates their supply, by using time-dependent taxes that are the same for all agents.

In the other two models, agents can trade money. Money is an asset that lasts forever, but pays no dividend. It plays no special role in transactions. In the third model, money is in positive supply. A government regulates its supply using lump-sum taxes. In the fourth model, there is no government. Agents can issue and redeem private money, subject to a period-by-period constraint on the difference between past issue and past redemption.

These models are designed to be closely related to ones already in the literature. The first model is essentially the famous Aiyagari-Bewley model of self-insurance. The second model is motivated by Aiyagari and McGrattan's (1998) study of the optimal quantity of government debt. The third model is a version of Lucas' (1980) pure currency economy. It is used by Imrohoroglu (1992) in her study of the welfare costs of inflation. The fourth model is more novel, although of course many authors have been interested in comparing the consequences of using inside instead of outside money (see, for example, Cavalcanti and Wallace (1999)).

The basic lesson of this prior literature is that the exact nature of the traded asset has important effects on model outcomes. In Aiyagari and McGrattan (1998) (and later Shin (2006)), public debt issue generates welfare costs that do not occur in models with private debt. Lucas (1980) argues that agents cannot achieve as much with money as with private debt, saying explicitly, "There is a sense in which money is a second-rate asset." Cavalcanti and Wallace (1999) argue that using inside (privately issued) money allows agents to achieve 
more than outside money.

In contrast, I prove the following equivalence theorem. Take an equilibrium in any of the four economies. Then, it is possible to specify the exogenous elements of the other three economies so that there is an outcome-equivalent equilibrium in each. Here, by "exogenous elements," I mean specifically:

1. borrowing limits in the first model

2. bond supplies in the second model

3. money supplies in the third model

4. money issue limits in the fourth model.

In fact, the equivalence is actually even stronger: in all of these outcome-equivalent equilibria, agents have identical choice sets as in the original equilibrium.

Why is my result so different from the lesson of the prior literature? In the earlier analyses, the models with different assets also impose different assumptions on the nature of what might be termed the repayment or collection technology. For example, in models with private risk-free debt, the borrower must make a repayment that is independent of the borrower's decisions or shocks. In essence, the lender is essentially able to impose a lumpsum tax on the borrower at the time of repayment. In models with public risk-free debt, like Aiyagari and McGrattan (1998), the government makes a repayment that is independent of any aggregate shocks. However, it is typically assumed that the government must use linear taxes to collect the resources for its repayments. This restriction to linear taxes means that government repayment of public debts must distort agents' decisions in a way that is not true of private debt repayment. The treatment of taxes in models with outside money is often even more drastic; thus, in their models, Lucas (1980), Cavalcanti and Wallace (1999) and Kocherlakota (2003) all assume that the government can use no taxes other than inflation taxes.

In this paper, I eliminate these differences across the models in their specification of the repayment technology. In particular, I assume in the models with public debt issue that the government is able to levy a head tax - that is, a lump-sum tax that is the same for all agents. (Note that given the potential heterogeneity in the model setting, the government 
cannot generally implement a first-best outcome using the (uniform) head tax.) Once I endow the government with this instrument, I can prove the equivalence theorem.

The theorem really contains two distinct results. First, I show that the public issue and private issue of bonds/money are equivalent to one another. In this equivalence, the above head tax plays a key role. In the models with public issue, the government uses a head tax that is exactly equal to the interest payment made by a borrower in the private-issue economy who holds the maximal level of debt in each period. It is in this sense that the collection powers of the private sector and public sector are the same. Of course, these collection powers may well be limited by enforcement problems of various kinds; the crucial assumption is that the enforcement problems are the same in the private and public sectors.

Second, the theorem shows that risk-free bonds and money are equivalent to one another. The key to this demonstration is that money can have a positive real rate of return even though it does not pay dividends. This price rise can occur in equilibrium in the third model if the government shrinks the supply of money using the head tax. The size of the needed head tax is exactly the same as in the economy with public debt issue. It can occur in the fourth model if the limits on net money issue are shrinking over time.

The theorem is related to Wallace's (1981) famous Modigliani-Miller theorem for open market operations. Wallace proves that the money/bond composition of a government's debt portfolio does not affect equilibrium outcomes. Like my theorem, Wallace's relies on two crucial assumptions. First, as noted above, the government must have access to lump-sum taxes. Second, money cannot have a transactions advantage over bonds. This assumption is not satisfied by cash-in-advance, money-in-the-utility function, or transaction cost models. Like Wallace's paper, mine is also closely related to Barro's (1974) analysis of government debt.

Taub (1994) poses the question, "Are currency and credit equivalent mechanisms?" that motivates this paper. As I do, he answers this question affirmatively. However, he confines his analysis to a rather special example (linear utility). Levine (1991) and Green and Zhou (2005) use linear utility examples to demonstrate how a government using public money issue can achieve a first-best outcome in a world in which agents experience shocks to their need for consumption. In their examples, the government achieves this good outcome by 
using an inflationary monetary policy. My theorem demonstrates that the government could instead use an appropriate debt policy, or that private agents could achieve this desirable outcome with appropriately set borrowing limits.

\section{Setup}

Consider an infinite horizon environment with a unit measure of agents in which time is indexed by the natural numbers. At the beginning of period 1, for each agent, Nature draws an infinite sequence $\left(\theta_{t}\right)_{t=1}^{\infty}$ from the set $\Theta^{\infty}$, where $\Theta$ is finite. The draws are i.i.d. across agents, with measure $\mu$. Hence, there is no aggregate risk. At the beginning of period $t$, a given agent observes his own realization of $\theta_{t}$; his information at date $t$ consists of the history $\theta^{t}=\left(\theta_{1}, \ldots, \theta_{t}\right)$.

The shocks affect individuals as follows. The typical agent has preferences of the form

$$
\sum_{t=1}^{\infty} \beta^{t-1} u\left(c_{t}, y_{t}, \theta_{t}\right)
$$

where $c_{t}$ is the agent's consumption in period $t, y_{t}$ is the agent's output in period $t$, and $0<\beta<1$. The agent's utility function $u$ is assumed to be strictly increasing in $c_{t}$, strictly decreasing in $y_{t}$, and is a function of the realization of $\theta_{t}$.

I then consider four different (possibly incomplete markets) trading structures embedded in this setting.

\section{A. Private-Bond Economy}

The first market structure is a private-bond economy. It is completely characterized by a borrowing limit sequence $B^{\text {priv }}=\left(B_{t+1}^{\text {priv }}\right)_{t=1}^{\infty}$, where $B_{t+1}^{\text {priv }} \in R_{+}$. (Note that the borrowing limits are the same for all agents in all periods.) At each date, the agents trade one-period risk-free real bonds in zero net supply for consumption. They are initially endowed with zero units of bonds each. Each agent's bond-holdings in period $t$ must be no smaller than $-B_{t+1}^{\text {priv }}$ (as measured in terms of consumption in that period).

In this economy, individuals take interest rates $r=\left(r_{t}\right)_{t=1}^{\infty}, r_{t} \in R$, as given and then choose consumption, output, and bond-holdings $(c, y, b)=\left(c_{t}, y_{t}, b_{t+1}\right)_{t=1}^{\infty},\left(c_{t}, y_{t}, b_{t+1}\right): \Theta^{t} \rightarrow$ 
$R_{+}^{2} \times R$. Hence, the agent's problem is

$$
\begin{aligned}
& \max _{(c, y, b)} E \sum_{t=1}^{\infty} \beta^{t-1} u\left(c_{t}, y_{t}, \theta_{t}\right) \\
& \text { s.t. } c_{t}\left(\theta^{t}\right)+b_{t+1}\left(\theta^{t}\right) \\
\leq & y_{t}\left(\theta^{t}\right)+b_{t}\left(\theta^{t-1}\right)\left(1+r_{t-1}\right) \forall\left(\theta^{t}, t \geq 1\right) \\
& \left\{b_{t+1}\left(\theta^{t}\right)+B_{t+1}^{\text {priv }}\right\}, c_{t}\left(\theta^{t}\right), y_{t}\left(\theta^{t}\right) \geq 0 \forall\left(\theta^{t}, t \geq 1\right) \\
& b_{1}=0
\end{aligned}
$$

An equilibrium in a private-bond economy $B^{\text {priv }}$ is a specification of $(c, y, b, r)$ such that $(c, y, b)$ solves the agent's problem given $r$ and markets clear for all $t$ :

$$
\begin{aligned}
& \int c_{t} d \mu=\int y_{t} d \mu \\
& \int b_{t+1} d \mu=0
\end{aligned}
$$

\section{B. Public-Bond Economy}

The second is a public-bond economy. At each date, there is a government that sells one-period risk-free real bonds. The economy is completely characterized by an exogenously specified bond supply sequence $B^{p u b}=\left(B_{t}^{p u b}\right)_{t=1}^{\infty}$, where $B_{t+1}^{p u b} \in R_{+}$and an initial period return $r_{0}$. The government raises $B_{t+1}^{p u b}$ units of consumption in period $t$ by selling one-period risk-free bonds. It collects $\tau_{t}^{b}$ units of consumption from each agent; the tax is the same for all agents, and is determined endogenously in equilibrium. ${ }^{1}$ Each agent is initially endowed with bonds that pay off $B_{1}^{p u b}\left(1+r_{0}\right)$ units of consumption. At each date, agents trade consumption and the government-issued bonds. Agents are not allowed to short-sell these bonds.

In this economy, the individuals take interest rates $r=\left(r_{t}\right)_{t=1}^{\infty}$ as given and then choose consumption, output, and bond-holdings. Hence, the individual's problem is

$$
\max _{(c, y, b)} E \sum_{t=1}^{\infty} \beta^{t-1} u\left(c_{t}, y_{t}, \theta_{t}\right)
$$

\footnotetext{
${ }^{1}$ Taxes are endogenously determined in this public-bond economy and in the public-money economy discussed in the next section. It is important to note that the main equivalence theorem is valid even if taxes are exogenously specified. I treat taxes as endogenous so as to ensure that the government flow budget constraint is satisfied for off-equilibrium interest rate/price sequences, as well as in equilibrium.
} 


$$
\begin{aligned}
& \text { s.t. } c_{t}\left(\theta^{t}\right)+b_{t+1}\left(\theta^{t}\right) \\
\leq & y_{t}\left(\theta^{t}\right)+b_{t}\left(\theta^{t}\right)\left(1+r_{t-1}\right)-\tau_{t}^{b o n d} \forall\left(\theta^{t}, t \geq 2\right) \\
& c_{1}\left(\theta_{1}\right)+b_{2}\left(\theta_{1}\right) \leq y_{1}\left(\theta_{1}\right)+B_{1}^{p u b}\left(1+r_{0}\right)-\tau_{1}^{b o n d} \forall \theta_{1} \\
& b_{t+1}\left(\theta^{t}\right), c_{t}\left(\theta^{t}\right), y_{t}\left(\theta^{t}\right) \geq 0 \forall \theta^{t}, t \geq 1
\end{aligned}
$$

An equilibrium in a public-bond economy $\left(B^{p u b}, r_{0}\right)$ is a specification of $\left(c, y, b, r, \tau^{b o n d}\right)$ such that $(c, y, b)$ solves the individual's problem given $\left(r, \tau^{b o n d}\right)$ and markets clear for all $t$ :

$$
\begin{aligned}
& \int c_{t} d \mu=\int y_{t} d \mu \text { for all } t \\
& \int b_{t+1} d \mu=B_{t+1}^{p u b} \text { for all } t
\end{aligned}
$$

Together, these imply that a government budget constraint holds at each date:

$$
\tau_{t}^{b}=-B_{t+1}^{p u b}+B_{t}^{p u b}\left(1+r_{t-1}\right)
$$

\section{Public-Money Economy}

The third economy is a public-money economy. By money, I mean an infinitely-lived asset that pays no dividends. Each agent is initially endowed with $M_{1}^{p u b}$ units of money. Then, the economy is completely characterized by an exogenously specified money supply sequence $M^{p u b}=\left(M_{t+1}^{p u b}\right)_{t=1}^{\infty}$, where $M_{t+1}^{p u b} \in R_{+}$. In period $t$, the government collects $\tau_{t}^{\text {mon }}$ units of consumption from each agent; again, the taxes are the same for all agents, and are determined endogenously in equilibrium. At each date, agents trade money and consumption; the government trades so as to ensure that there are $M_{t+1}^{p u b}$ units of money outstanding.

In this economy, the individuals take money prices $p$ as given and then choose consumption, output, and money-holdings. Hence, the individual's problem is

$$
\begin{aligned}
& \max _{(c, y, M)} E \sum_{t=1}^{\infty} \beta^{t-1} u\left(c_{t}, y_{t}, \theta_{t}\right) \\
& \text { s.t. } c_{t}\left(\theta^{t}\right)+M_{t+1}\left(\theta^{t}\right) p_{t} \\
\leq & y_{t}\left(\theta^{t}\right)+M_{t}\left(\theta^{t-1}\right) p_{t}-\tau_{t}^{\text {mon }} \forall \theta^{t}, t \geq 2 \\
& c_{1}\left(\theta_{1}\right)+M_{2}\left(\theta_{1}\right) p_{1} \leq y_{1}\left(\theta_{1}\right)+M_{1}^{p u b} p_{1}-\tau_{1}^{m o n} \forall \theta_{1} \\
& M_{t+1}\left(\theta^{t}\right), c_{t}\left(\theta^{t}\right), y_{t}\left(\theta^{t}\right) \geq 0 \forall\left(\theta^{t}, t \geq 1\right)
\end{aligned}
$$


An equilibrium in a public-money economy $\left(M^{p u b}\right)$ is a specification of $\left(c, y, M, p, \tau^{\text {mon }}\right)$ such that $(c, y, M)$ solves the individual's problem given $\left(p, \tau^{\text {mon }}\right)$ and markets clear for all $t$ :

$$
\begin{aligned}
& \int c_{t} d \mu=\int y_{t} d \mu \\
& \int M_{t+1} d \mu=M_{t+1}^{p u b}
\end{aligned}
$$

Again, a government budget constraint is implied at each date by market-clearing:

$$
\tau_{t}^{m o n}=M_{t}^{p u b} p_{t}-M_{t+1}^{p u b} p_{t}
$$

There is no cash-in-advance constraint or any transaction cost advantage associated with money in this setting.

\section{Private Money Economy}

The fourth and final economy is a private-money economy. In this economy, there is no government. Agents are able to issue their money in exchange for consumption, and redeem others' monies in exchange for consumption. However, in each history, they face an exogenous upper bound on the net amount of money issue that they have done in their lifetimes. The economy is completely characterized by the exogenous upper bound process $M^{\text {priv }}=\left(M_{t+1}^{\text {priv }}\right)_{t=1}^{\infty}$, where $M_{t+1}^{\text {priv }} \in R_{+}$.

In this economy, the individuals take money prices $p$ as given and then choose consumption, how much money to issue and how much money to redeem. (I assume that all monies are traded at the same price $p$; there may be other equilibria in which this restriction is not satisfied.) Hence, the individual's problem is

$$
\begin{aligned}
& \max _{\left(c, y, M^{i s s}, M^{\text {red }}\right)} E \sum_{t=1}^{\infty} \beta^{t-1} u\left(c_{t}, y_{t}, \theta_{t}\right) \\
& \text { s.t. } c_{t}\left(\theta^{t}\right)+M_{t+1}^{r e d}\left(\theta^{t}\right) p_{t} \\
\leq & y_{t}\left(\theta^{t}\right)+M_{t+1}^{i s s}\left(\theta^{t}\right) p_{t} \forall \theta^{t}, t \geq 1 \\
& M_{t+1}^{i s s}\left(\theta^{t}\right), M_{t+1}^{r e d}\left(\theta^{t}\right), c_{t}\left(\theta^{t}\right), y_{t}\left(\theta^{t}\right) \geq 0 \text { for all } \theta^{t}, t \\
& \sum_{s=1}^{t}\left[M_{s+1}^{i s s}\left(\theta^{s}\right)-M_{s+1}^{r e d}\left(\theta^{s}\right)\right] \leq M_{t+1}^{\text {priv }} \forall \theta^{t}, t \geq 1
\end{aligned}
$$

An equilibrium in a private-money economy $\left(M^{\text {priv }}\right)$ is a specification of $\left(c, y, M^{r e d}, M^{i s s}, p\right)$ 
such that $\left(c, y, M^{r e d}, M^{i s s}, p\right)$ solves the individual's problem and markets clear for all $t$ :

$$
\begin{aligned}
& \int c_{t} d \mu=\int y_{t} d \mu \\
& \int M_{t+1}^{r e d} d \mu=\int M_{t+1}^{i s s} d \mu
\end{aligned}
$$

Again, there is no cash-in-advance constraint or transaction cost advantages associated with money in this setting.

\section{Example Economy}

In this section, I work through an example of the above general structure that illustrates the general equivalence theorem that follows in the next section. I start with an equilibrium in a private-bond economy. I then construct a public-bond economy, a publicmoney economy, and a private-money economy. I show that in each of these economies, there is an equilibrium with the same consumption allocation as the original, private-bond, equilibrium. Even more strongly, agents have exactly the same budget sets in each of these equilibria.

In the example, output is inelastically supplied. Half of the agents receive an endowment stream of the form $(1+h, 1,1, \ldots)$ and the other half get an endowment stream of the form $(1-h, 1,1, \ldots)$, where $1>h>0$. I will call the first half "rich" and the second half "poor." The agents have identical preferences of the form

$$
\sum_{t=1}^{\infty} \beta^{t-1} \ln \left(c_{t}\right)
$$

where $1>\beta>0$.

\section{A. Private-Bond Economy}

Consider first a private-bond economy in which the borrowing limit $B_{t+1}^{\text {priv }}$ is constant at $\beta \lambda(1-\beta)^{-1}$, where $(1-\beta)<\lambda<1$. We can construct an equilibrium in this economy as follows. Set the interest rate $r_{t}$ to be constant at $1 / \beta-1$. Rich agents consume a constant amount $c^{r}$, where

$$
c^{r}=(1+h)(1-\beta)+\beta=1+h(1-\beta)
$$


Rich agents' bond-holdings $b_{t+1}^{r}$ equal

$\beta h$

for period $t \geq 1$. Poor agents consume a constant amount $c^{p}=2-c^{r}$. Poor agents' bondholdings $b_{t+1}^{p}$ equal

$$
-h \beta
$$

for period $t \geq 1$. Note that the borrowing limit has been chosen so that it never binds in equilibrium.

It is readily checked that the above specification forms an equilibrium. Markets clear. The agents' flow budget constraints are satisfied because

$$
\begin{aligned}
c^{r}+b_{2}^{r}-1-h & =0 \\
c^{r}+b_{t+1}^{r}-1-b_{t}^{r} \beta^{-1} & =0 \text { for all } t \geq 2
\end{aligned}
$$

and similarly for poor agents. Because the borrowing limit does not bind, the agents' Euler equations are satisfied. We need only check the agents' transversality conditions, which are satisfied because the two limits

$$
\begin{aligned}
& \lim _{t \rightarrow \infty} \beta^{t-1} u^{\prime}\left(c^{r}\right)\left(b_{t+1}^{r}-2 \beta\right) \\
& \lim _{t \rightarrow \infty} \beta^{t-1} u^{\prime}\left(c^{p}\right)\left(b_{t+1}^{p}-2 \beta\right)
\end{aligned}
$$

are both equal to zero.

\section{B. Public-Bond Economy}

I now want to design a public-bond economy with an outcome-equivalent equilibrium. In a public-bond economy, agents are not allowed to borrow. Hence, to get a non-autarkic equilibrium, there must be a positive amount of debt outstanding. I set $B_{t}^{\text {pub }}=\beta \lambda(1-\beta)^{-1}$ (the private economy borrowing limit) for all $t$ and $r_{0}=1 / \beta-1$. As above, we can construct an equilibrium in this economy in which the equilibrium interest rate $r_{t}$ is constant at $1 / \beta-1$. Rich agents consume $c^{r}$ (as defined above) in each period, and poor agents consume $c^{p}$ in 
each period. Each agent pays a lump-sum tax $\tau_{t}^{b}=\lambda$ at every date. Then, in period $t \geq 1$, rich agents' bond-holdings $b_{t+1}^{r}$ equal

$$
\beta h+\beta \lambda(1-\beta)^{-1}
$$

and poor agents' bond-holdings $b_{t+1}^{p}$ equal

$$
-\beta h+\beta \lambda(1-\beta)^{-1}
$$

Note that the agents' bond-holdings are always positive.

Again, it is simple to verify that these interest rates and quantities form an equilibrium. Markets clear. The rich agent's flow budget constraint in period 1 is satisfied because

$$
\begin{aligned}
& c^{r}+b_{2}^{r}-1-h-B_{1}^{\text {pub }} \beta^{-1}+\tau^{\text {bond }} \\
= & 1+h(1-\beta)+h \beta+\beta \lambda(1-\beta)^{-1}-1-h-\lambda(1-\beta)^{-1}+\lambda \\
= & 0 .
\end{aligned}
$$

The rich agent's flow budget constraint in period $t>1$ is satisfied because

$$
\begin{aligned}
& c^{r}+b_{t+1}^{r}-1-b_{t}^{r} \beta^{-1}+\tau^{\text {bond }} \\
= & 1+h(1-\beta)+h \beta+\beta \lambda(1-\beta)^{-1}-1-h-\lambda(1-\beta)^{-1}+\lambda \\
= & 0 .
\end{aligned}
$$

We can check the poor agents' flow constraints in a similar fashion.

The agents' Euler equations are clearly satisfied, because their no-short-sales constraint never binds. Finally, we need to verify the transversality conditions:

$$
\begin{aligned}
& \lim _{t \rightarrow \infty} \beta^{t} u^{\prime}\left(c^{r}\right) b_{t+1}^{r}=0 \\
& \lim _{t \rightarrow \infty} \beta^{t} u^{\prime}\left(c^{p}\right) b_{t+1}^{p}=0
\end{aligned}
$$

Hence, there is an equilibrium in this public-bond economy with the same consumption allocation as the original, private-bond, equilibrium. 


\section{Public-Money Economy}

I now want to design a public-money economy with an outcome-equivalent equilibrium. Clearly, the gross rate of return on money must be $\beta^{-1}$, in order to satisfy the agents' firstorder conditions. Since money pays no dividend, this rate of return implies that the price of money must rise at rate $\beta^{-1}$. At the same time, we need the rich agents' transversality condition:

$$
\lim _{t \rightarrow \infty} \beta^{t} u^{\prime}\left(c^{r}\right) M_{t+1}^{r} p_{t}=0
$$

to be satisfied. This requires that the money stock must converge to zero over time.

Given these considerations, consider a public-money economy in which $M_{t}^{p u b}=\beta^{t} \lambda(1-$ $\beta)^{-1}$. I claim that there is an equilibrium in this economy in which $p_{t}=\beta^{-t}$ for all $t$. Rich agents consume $c^{r}$ in each period, and poor agents consume $c^{p}$ in each period. As in the public-bond economy, each agent pays a lump-sum tax $\tau_{t}^{m o n}=\lambda$ at every date. Then, in period $t \geq 1$, rich agents' money-holdings $M_{t+1}^{r}$ equal

$$
\beta^{t+1} h+\beta^{t+1} \lambda(1-\beta)^{-1}
$$

and poor agents' bond-holdings $M_{t+1}^{p}$ equal

$$
-\beta^{t+1} h+\beta^{t+1} \lambda(1-\beta)^{-1}
$$

To verify the claim that these prices and quantities form an equilibrium, note that markets clear and that individual Euler equations are satisfied. Clearly, the transversality conditions are also satisfied, because the money supply converges to zero. Finally, we can verify that the flow budget constraints are satisfied. In period 1, the rich agents' flow constraints are:

$$
\begin{aligned}
& c^{r}+p_{1} M_{2}^{r}-1-h-p_{1} M_{1}^{r}+\tau^{\text {mon }} \\
= & 1+h(1-\beta)+\beta^{-1}\left(\beta^{2} h+\beta^{2} \lambda(1-\beta)^{-1}\right)-1-h-\lambda(1-\beta)^{-1}+\lambda \\
= & 0 .
\end{aligned}
$$

In period $t>1$, the rich agents' flow constraints are

$$
c^{r}+p_{t} M_{t+1}^{r}-1-p_{t} M_{t}^{r}+\tau^{m o n}
$$




$$
\begin{aligned}
& =1+h(1-\beta)+\beta^{-t}\left(\beta^{t+1} h+\beta^{t+1} \lambda(1-\beta)^{-1}\right)-1-\left(h+\lambda(1-\beta)^{-1}\right)+\lambda \\
& =0
\end{aligned}
$$

The poor agents' flow constraints are similar.

Money pays no dividend and has no liquidity benefits. Nonetheless, money has a positive value in this equilibrium. This positive value seems to create the possibility for an arbitrage, in which a given agent permanently reduces his money-holdings by a small amount $\varepsilon$. However, this arbitrage is infeasible, because the supply of money eventually falls to zero.

\section{Private-Money Economy}

Finally, I design a private-money economy that induces the same equilibrium consumption allocation. Consider a private-money economy in which $M_{t+1}^{\text {priv }}=\beta^{t+1} \lambda(1-\beta)^{-1}$. Then, I claim that there is an equilibrium in this economy in which $p_{t}=\beta^{-t}$ for all $t$. Rich agents consume $c^{r}$ in each period, and poor agents consume $c^{p}$ in each period. In period 1 , poor agents issue $M_{2}^{i s s, p}=\beta^{2} h$ and rich agents redeem $M_{2}^{\text {red,r }}=\beta^{2} h$. In period $t>1$, poor agents redeem $M_{t+1}^{r e d, p}=h(1-\beta) \beta^{t}$ and rich agents issue $M_{t+1}^{i s s, r}=h(1-\beta) \beta^{t}$. Note that in period $t$,

$$
\sum_{s=1}^{t}\left(M_{s+1}^{i s s, p}-M_{s+1}^{r e d, p}\right)=\beta^{2} h-\beta^{2} h(1-\beta)-\beta^{3} h(1-\beta)-\ldots-\beta^{t} h(1-\beta)=\beta^{t+1} h
$$

which is less than $\beta^{t+1} \lambda(1-\beta)^{-1}$. In this private-money economy, neither rich nor poor agents ever have net money issue equal to $\beta^{t}$. Hence, the bound on money issue never binds in equilibrium.

We can verify the validity of this putative equilibrium as follows. Markets clear, and the agents' Euler equations are clearly satisfied. In period 1, the rich agents' flow budget constraints are

$$
\begin{aligned}
& c^{r}+p_{1} M_{2}^{r e d, r}-1-h-p_{1} M_{2}^{i s s, r} \\
= & 1+h(1-\beta)+\beta h-1-h \\
= & 0 .
\end{aligned}
$$


In period $t>1$, the rich agents' flow budget constraints are

$$
\begin{aligned}
& c^{r}+p_{t} M_{t+1}^{r e d, r}-1-p_{t} M_{t+1}^{i s s, r} \\
= & 1+h(1-\beta)-h(1-\beta)-1 \\
= & 0 .
\end{aligned}
$$

The poor agents' flow constraints can be checked in a similar fashion.

Finally, we need to verify the agents' transversality conditions. To do so, note that

$$
\begin{aligned}
& \lim _{t \rightarrow \infty} \beta^{t} u^{\prime}\left(c^{r}\right) p_{t}\left\{-\sum_{s=1}^{t}\left[M_{s+1}^{i s s}-M_{s+1}^{r e d}\right]+M_{t+1}^{\text {priv }}\right\} \\
= & \lim _{t \rightarrow \infty} \beta^{t} u^{\prime}\left(c^{r}\right) p_{t}\left\{\beta^{t+1} h\right\}\left[\lambda(1-\beta)^{-1}-1\right] \\
= & 0
\end{aligned}
$$

In this economy, money has a positive value and pays no dividends. Why is it not optimal for an agent to issue $\varepsilon$ units more money in period 1? Issuing $\varepsilon$ more units of money in period 1 means that the agent's net money issue would be $\varepsilon+\beta^{t+1} h$ in period $t$. But for large $t$, this amount will exceed the upper bound on money issue. Put another way, even though it never binds, the money issue constraint is structured so that agents must eventually redeem whatever currency they have issued.

\section{E. Budget Set Equivalence}

The arguments above establish that the equilibrium outcomes are identical across the four economies. But, with some algebra, it is possible to prove an even stronger equivalence: the equilibrium budget sets of $(c, y)$ are the same across the four economies. Agents are confronted with exactly the same sets of possible choices in the four economies. As we shall see, this deeper isomorphism can be generalized.

\section{An Equivalence Theorem}

In this section, I prove the main theorem in the paper. The theorem starts with an equilibrium $(c, y, b, r)$ in a private-bond economy defined by $B^{\text {priv }}$. It then shows how, by translating the bond-holdings upward by $B^{\text {priv }}$ and crafting taxes in the right way, we can 
get an outcome-equivalent equilibrium in the public-bond economy. The key to the theorem is that these taxes equal the net interest payments on the bond-holding limits.

Then, the theorem goes on to show that, by setting monetary policy in the right way, we can design an outcome-equivalent equilibrium in the public-money economy. The key here is that monetary policy must be designed so that the price level falls at the rate of interest, and the real value of aggregate money-holdings always equals aggregate bond-holdings. As we will see later, this will typically mean that aggregate money-holdings will be shrinking (but not necessarily at the Friedman Rule $1 / \beta-1$ ).

Finally, the theorem turns to the private-money economy. Here, I set the upper bounds on net real money issue equal to the borrowing limit in the private-bond economy. By doing so, I can induce an outcome-equivalent equilibrium in this setting. ${ }^{2}$

TheOREM 1. Suppose $\left(r_{t-1}, p_{t}, B_{t+1}^{\text {priv }}, B_{t}^{\text {pub }}, \tau_{t}^{\text {bond }}, M_{t}^{\text {pub }}, \tau_{t}^{\text {mon }}, M_{t+1}^{\text {priv }}\right)_{t=1}^{\infty}$ are sequences such that for all t:

$$
\begin{aligned}
p_{t} & =\left(1+r_{t-1}\right) p_{t-1} ; p_{1}=M_{1}^{p u b}\left(1+r_{0}\right)^{-1} / B_{1}^{p u b} \\
B_{t+1}^{\text {priv }} & =B_{t+1}^{\text {pub }}=M_{t+1}^{\text {pub }} p_{t}=M_{t+1}^{\text {priv }} p_{t} \\
\tau_{t}^{\text {bond }} & =\tau_{t}^{\text {mon }}=B_{t}^{\text {pub }}\left(1+r_{t-1}\right)-B_{t+1}^{p u b}
\end{aligned}
$$

Then the following four statements are equivalent.

1. $(c, y, b, r)$ is an equilibrium in a private-bond economy defined by $B^{\text {priv }}$.

2. $\left(c, y, b+B^{\text {priv }}, r, \tau^{\text {bond }}\right)$ is an equilibrium in a public-bond economy defined by $B^{p u b}$ and $r_{0}$.

3. $\left(c, y,\left(b+B^{\text {priv }}\right) / p, p, \tau^{\text {mon }}\right)$ is an equilibrium in a public-money economy defined by $M^{p u b}$.

4. $\left(c, y, M^{r e d}, M^{i s s}, p\right)$ is an equilibrium in a private-money economy defined by $M^{\text {priv }}$, where for all $t$ :

$$
\sum_{s=1}^{t}\left[M_{s+1}^{r e d}\left(\theta^{s}\right)-M_{s+1}^{i s s}\left(\theta^{s}\right)\right]=b_{t+1} / p_{t}
$$

for all $\theta^{s}$.

\footnotetext{
${ }^{2}$ The proof of this theorem relies on techniques similar to those that I use in Kocherlakota (forthcoming).
} 
Proof. I first prove the equivalence of statements 1 and 2. Pick an element $(\widehat{c}, \widehat{b})$ of an agent's budget set in the private-bond economy. Then, define

$$
\widehat{b}_{t+1}^{\prime}\left(\theta^{t}\right)=\widehat{b}_{t+1}\left(\theta^{t}\right)+B_{t+1}^{p r i v}, t \geq 1, \text { all } \theta^{t}
$$

My claim is that $\left(\widehat{c}, \widehat{y}, \widehat{b}^{\prime}\right)$ is in the agent's budget set in the public-bond economy. Obviously, $\widehat{b}_{t+1}^{\prime}\left(\theta^{t}\right) \geq 0$, because $\widehat{b}_{t+1}\left(\theta^{t}\right) \geq-B_{t+1}^{\text {priv }}$. Note that for $t \geq 2$

$$
\begin{aligned}
& \widehat{c}_{t}\left(\theta^{t}\right)+\widehat{b}_{t+1}^{\prime}\left(\theta^{t}\right)-\widehat{y}_{t}\left(\theta^{t}\right)-\left(1+r_{t-1}\right) \widehat{b}_{t}^{\prime}\left(\theta^{t-1}\right)+\tau_{t}^{\text {bond }} \\
= & \widehat{c}_{t}\left(\theta^{t}\right)+\widehat{b}_{t+1}\left(\theta^{t}\right)+B_{t+1}^{\text {priv }} \\
& -\widehat{y}_{t}\left(\theta^{t}\right)-\left(1+r_{t-1}\right) \widehat{b}_{t}\left(\theta^{t-1}\right)-\left(1+r_{t-1}\right) B_{t}^{\text {priv }}+\tau_{t}^{\text {bond }} \\
= & \widehat{c}_{t}\left(\theta^{t}\right)+\widehat{b}_{t+1}\left(\theta^{t}\right)-\widehat{y}_{t}\left(\theta^{t}\right)-\left(1+r_{t-1}\right) \widehat{b}_{t}\left(\theta^{t-1}\right) \\
\leq & 0 \text { for all } \theta^{t}
\end{aligned}
$$

We can use similar logic to check the flow budget constraint for $t=1$ :

$$
\begin{aligned}
& \widehat{c}_{1}\left(\theta_{1}\right)+\widehat{b}_{2}^{\prime}\left(\theta_{1}\right)-\widehat{y}_{1}\left(\theta_{1}\right)-B_{1}^{\text {pub }}\left(1+r_{0}\right)+\tau_{1}^{\text {bond }} \\
= & \widehat{c}_{1}\left(\theta_{1}\right)+\widehat{b}_{2}\left(\theta_{1}\right)+B_{2}^{\text {priv }}-\widehat{y}_{1}\left(\theta_{1}\right)-B_{1}^{p u b}\left(1+r_{0}\right)+\tau_{1}^{\text {bond }} \\
= & \widehat{c}_{1}\left(\theta_{1}\right)+\widehat{b}_{2}\left(\theta_{1}\right)-\widehat{y}_{1}\left(\theta_{1}\right) \leq 0
\end{aligned}
$$

for all $\left(\theta_{1}\right)$. Running the steps in reverse establishes the converse. Hence, the agent's budget sets are $(c, y)$-equivalent in the two economies. But it is then straightforward to see that statements 1 and 2 are equivalent.

I now prove the equivalence of statements 2 and 3 . Pick an element $\left(\widehat{c}, \widehat{y}, \widehat{b}^{\prime}\right)$ of an agent's budget set in the public-bond economy. Define $\widehat{M}_{t+1}=\widehat{b}_{t+1}^{\prime} / p_{t}$. I claim that $(\widehat{c}, \widehat{y}, \widehat{M})$ is in the agent's budget set in the public-money economy. Then for all $\theta^{t}, t \geq 2$ :

$$
\begin{aligned}
& \widehat{c}_{t}\left(\theta^{t}\right)+\widehat{M}_{t+1}\left(\theta^{t}\right) p_{t}-\widehat{y}_{t}\left(\theta^{t}\right)-\widehat{M}_{t}\left(\theta^{t-1}\right) p_{t}+\tau_{t}^{m o n} \\
= & \widehat{c}_{t}\left(\theta^{t}\right)+\widehat{b}_{t+1}^{\prime}\left(\theta^{t}\right)-\widehat{y}_{t}\left(\theta^{t}\right)-\left(1+r_{t-1}\right) \widehat{M}_{t}\left(\theta^{t}\right) p_{t-1}+\tau_{t}^{\text {bond }} \\
= & \widehat{c}_{t}\left(\theta^{t}\right)+\widehat{b}_{t+1}^{\prime}\left(\theta^{t}\right)-\widehat{y}_{t}\left(\theta^{t}\right)-\left(1+r_{t-1}\right) \widehat{b}_{t}^{\prime}\left(\theta^{t}\right)+\tau_{t}^{b o n d} \\
\leq & 0
\end{aligned}
$$


In period 1 , we can verify

$$
\begin{aligned}
& \widehat{c}_{1}\left(\theta_{1}\right)+\widehat{M}_{2}\left(\theta_{1}\right) p_{1}-\widehat{y}_{1}\left(\theta_{1}\right)-M_{1}^{p u b} p_{1}+\tau_{1}^{m o n} \\
= & \widehat{c}_{1}\left(\theta_{1}\right)+\widehat{b}_{2}^{\prime}\left(\theta_{1}\right)-\widehat{y}_{1}\left(\theta_{1}\right)-B_{1}^{p u b}+\tau_{1}^{\text {bond }} \\
\leq & 0
\end{aligned}
$$

for all $\left(\theta_{1}\right)$. We can run the logic in reverse to check the converse. Thus, the agent's budget sets are $(c, y)$-equivalent; this in turn establishes that statements 2 and 3 are equivalent.

Finally, I prove the equivalence of statements 1 and 4 . Pick an element $(\widehat{c}, \widehat{y}, \widehat{b})$ of an agent's budget set in the private-bond economy. Then, define

$$
\begin{aligned}
& M_{t+1}^{\text {red }}\left(\theta^{t}\right)=\max \left(\widehat{b}_{t+1}\left(\theta^{t}\right)-\left(1+r_{t-1}\right) \widehat{b}_{t}\left(\theta^{t-1}\right), 0\right) / p_{t}, t \geq 2 \\
& M_{t+1}^{i s s}\left(\theta^{t}\right)=\max \left(\left(1+r_{t-1}\right) \widehat{b}_{t}\left(\theta^{t-1}\right)-\widehat{b}_{t+1}\left(\theta^{t}\right), 0\right) / p_{t}, t \geq 2 \\
& M_{2}^{r e d}\left(\theta_{1}\right)=\max \left(\widehat{b}_{2}\left(\theta_{1}\right), 0\right) / p_{1} \\
& M_{2}^{i s s}\left(\theta_{1}\right)=\max \left(-\widehat{b}_{2}\left(\theta_{1}\right), 0\right) / p_{1}
\end{aligned}
$$

I claim that $\left(\widehat{c}, \widehat{y}, M^{r e d}, M^{i s s}\right)$ is in the agent's budget set in the private-money economy. In period $t>1$ :

$$
\begin{aligned}
& \widehat{c}_{t}\left(\theta^{t}\right)+M_{t+1}^{r e d}\left(\theta^{t}\right) p_{t}-\widehat{y}_{t}\left(\theta^{t}\right)-M_{t+1}^{i s s}\left(\theta^{t}\right) p_{t} \\
= & \widehat{c}_{t}\left(\theta^{t}\right)+\widehat{b}_{t+1}\left(\theta^{t}\right)-\left(1+r_{t-1}\right) \widehat{b}_{t}\left(\theta^{t}\right)-\widehat{y}_{t}\left(\theta^{t}\right) \\
\leq & 0
\end{aligned}
$$

for all $\left(\theta^{t}\right)$ and in period 1 , for all $\left(\theta_{1}\right)$ :

$$
\begin{aligned}
& \widehat{c}_{1}\left(\theta_{1}\right)+M_{2}^{r e d}\left(\theta_{1}\right) p_{1}-\widehat{y}_{1}\left(\theta_{1}\right)-M_{2}^{i s s}\left(\theta_{1}\right) p_{1} \\
= & \widehat{c}_{1}+\widehat{b}_{2}\left(\theta_{1}\right)-\widehat{y}_{1}\left(\theta_{1}\right) \\
\leq & 0
\end{aligned}
$$


Note too that:

$$
\begin{aligned}
& \sum_{s=1}^{t}\left(M_{s+1}^{r e d}\left(\theta^{s}\right)-M_{s+1}^{i s s}\left(\theta^{s}\right)\right) \\
= & \sum_{s=1}^{t}\left[\widehat{b}_{s+1}\left(\theta^{s}\right)-\left(1+r_{s-1}\right) \widehat{b}_{s}\left(\theta^{s-1}\right)\right] / p_{s} \\
= & \sum_{s=1}^{t}\left[\widehat{b}_{s+1}\left(\theta^{s}\right) / p_{s}-\widehat{b}_{s}\left(\theta^{s}\right) / p_{s-1}\right] \\
= & \widehat{b}_{t+1}\left(\theta^{s}\right) / p_{t} \\
\geq & -B_{t+1}^{\text {priv }} / p_{t} \\
= & -M_{t+1}^{\text {priv }}
\end{aligned}
$$

This confirms that the budget-feasible consumptions in the private-bond economy are a subset of the budget-feasible consumption set in the private-money economy. Conversely, suppose $\left(\widehat{c}, \widehat{y}, M^{r e d}, M^{i s s}\right)$ is in the agent's budget set in the private-money economy. Then define:

$$
\widehat{b}_{t+1}\left(\theta^{s}\right)=p_{t} \sum_{s=1}^{t}\left(M_{s+1}^{r e d}\left(\theta^{s}\right)-M_{s+1}^{i s s}\left(\theta^{s}\right)\right)
$$

I claim that $(\widehat{c}, \widehat{y}, \widehat{b})$ is budget-feasible in the private-bond economy. In period $t>1$, for any $\left(\theta^{t}\right)$ :

$$
\begin{aligned}
& \widehat{c}_{t}\left(\theta^{t}\right)+\widehat{b}_{t+1}\left(\theta^{t}\right)-\widehat{y}_{t}\left(\theta^{t}\right)-\widehat{b}_{t}\left(\theta^{t}\right)\left(1+r_{t-1}\right) \\
= & \widehat{c}_{t}\left(\theta^{t}\right)+p_{t} \sum_{s=1}^{t}\left(M_{s+1}^{r e d}\left(\theta^{s}\right)-M_{s+1}^{i s s}\left(\theta^{s}\right)\right)-\widehat{y}_{t}\left(\theta^{t}\right)-p_{t} \sum_{s=1}^{t-1}\left(M_{s+1}^{r e d}\left(\theta^{s}, y^{s}\right)-M_{s+1}^{i s s}\left(\theta^{s}, y^{s}\right)\right) \\
= & \widehat{c}_{t}\left(\theta^{t}, y^{t}\right)+p_{t}\left(M_{t+1}^{r e d}\left(\theta^{t}\right)-M_{t+1}^{i s s}\left(\theta^{t}\right)\right)-\widehat{y}_{t}\left(\theta^{t}\right) \\
\leq & 0
\end{aligned}
$$

In period 1 , for any $\left(\theta_{1}\right)$ :

$$
\begin{aligned}
& \widehat{c}_{1}\left(\theta_{1}\right)+\widehat{b}_{2}\left(\theta_{1}\right)-\widehat{y}_{1}\left(\theta_{1}\right) \\
= & \widehat{c}_{1}\left(\theta_{1}, y_{1}\right)+p_{1}\left(M_{2}^{r e d}\left(\theta_{1}\right)-M_{2}^{i s s}\left(\theta_{1}\right)\right)-\widehat{y}_{1}\left(\theta_{1}\right) \\
\leq & 0
\end{aligned}
$$

Agent $j$ 's bond-holdings $\widehat{b}$ clearly satisfy the borrowing limit $-B^{\text {priv }}$. Hence, $(\widehat{c}, \widehat{y}, \widehat{b})$ is budget- 
feasible in the private-bond economy. The budget sets are $(c, y)$-equivalent. It follows that Statements 1 and 4 are equivalent. QED

\section{Discussion}

In this section, I discuss several aspects of Theorem 1.

\section{A. Equivalences}

Theorem 1 establishes two kinds of equivalences. The first is between private issue and public issue (of money or bonds). Consider, for example, a private-bond economy in which agents have a constant borrowing limit $B^{\text {priv }}$. In this economy, all agents begin with the same holdings of bonds (zero). They can run down their holdings to $-B^{\text {priv }}$. Now, consider a public-bond economy in which all agents begin their lives by holding $B^{\text {priv }}$ units of bonds. They face taxes with present value equal to $B^{\text {priv }}$ and can run down their holdings to zero. In the public-bond economy, agents' initial wealths are the same as in the private debt economy. As well, they can run down their initial bond-holdings by exactly the same amount ( $B^{\text {priv }}$ ) as in the private debt economy. Hence, their budget sets are the same in the two kinds of economies. $^{3}$

The second kind of equivalence is between monetary economies and bond economies. Consider a public-bond economy in which the equilibrium rate of return is constant at $r>0$, and the value of outstanding public debt is constant at $B^{p u b}$. Theorem 1 designs a publicmoney economy in which the equilibrium rate of return is also $r$, and value of outstanding public obligations (now in the form of money) is $B^{p u b}$. In this public-money economy, the price of money must rise at rate $r$. Hence, the quantity of money must fall at this same rate. The government sucks out this money using the same taxes that it used to finance its interest payments in the public-bond economy.

It is worth pointing out that the proof of Theorem 1 establishes a stronger result than Theorem 1 itself. The statement of Theorem 1 is that the equilibrium outcomes across the

\footnotetext{
${ }^{3}$ It is possible to extend Theorem 1 to include model economies in which agents can trade both public and private debt. In particular, suppose there is an equilibrium $(c, y, b, r)$ in a private-bond economy defined by the sequence $B^{\text {priv }}$. Suppose too that there is an economy in which the sequence of supplies of outside debt is given by $B^{\text {publ }}$ and the borrowing limit sequence is given by $B^{\text {priv' }}$. Then, there is an equilibrium with allocation $(c, y)$ in this latter private-public bond economy if $B^{p u b \prime}+B^{\text {priv' }}=B^{\text {priv }}$ in all periods.
} 
four economies are the same in terms of $(c, y)$. Actually, the proof establishes a much stronger result: the equilibrium budget sets of $(c, y)$ are the same in the four economies. Agents face exactly the same choice problems in the four equilibria of the four economies.

It is possible to extend Theorem 1 to include model economies in which agents can trade both public and private debt. In particular, suppose there is an equilibrium $(c, y, b, r)$ in a private-bond economy defined by the sequence $B^{\text {priv }}$. Suppose too that there is an economy in which the sequence of supplies of outside debt is given by $B^{p u b \prime}$ and the borrowing limit sequence is given by $B^{\text {priv' }}$. Then, there is an equilibrium with allocation $(c, y)$ in this latter

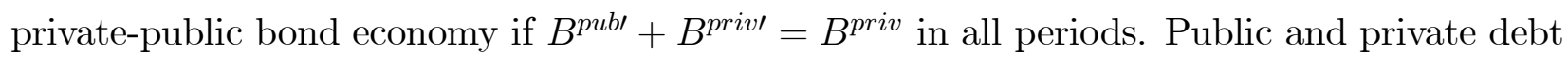
are perfect substitutes.

\section{B. Lump-Sum Taxes}

A key element of the proof of Theorem 1 is that the taxes $\tau^{\text {mon }}$ and $\tau^{\text {bond }}$ don't depend on $y$; hence, they are lump-sum. These lump-sum taxes simply give the government similar collection powers to those of the private sector. In particular, consider an equilibrium $(c, y, b, r)$ in a private bond economy defined by $B^{\text {priv }}$. In this equilibrium, a borrower may owe as much as

$$
B_{t+1}^{\text {priv }}\left(1+r_{t}\right)
$$

in period $(t+1)$. The borrower can only borrow up to $B_{t+2}^{\text {priv }}$ to repay this loan. Hence, a lender must be able to collect

$$
B_{t+1}^{\text {priv }}\left(1+r_{t}\right)-B_{t+2}^{\text {priv }}
$$

in period $(t+1)$. This collection limit is independent of decisions about $(c, y)$ being made by the borrower. In this sense, lenders are able to levy a lump-sum tax on the borrower equal to $B_{t+1}^{\text {priv }}\left(1+r_{t}\right)-B_{t+2}^{\text {priv }}$ in period $(t+1)$.

This collection limit is exactly equal to $\tau^{\text {bond }}$ and $\tau^{\text {mon }}$ in the equivalent public bond and money economies constructed in Theorem 1. Hence, by assuming that the government can levy taxes equal to $\tau^{\text {bond }}$ and $\tau^{\text {mon }}$, I am assuming that the government can levy the same lump-sum taxes as can a private lender. This means, for example, that the private and public sector must face the same limits on enforcement across the two kinds of models. 
In reality, governments can use a broader range of taxes than is assumed in the above economies. More generally, suppose that in all four economies, the government can use any element of a class $C$ of tax schedules $\psi=\left\{\psi_{t}\right\}_{t=1}^{\infty}$, where an agent who has production history $y_{t}$ in period $t$ pays a tax $\psi_{t}\left(y^{t}\right)$. We can prove a version of Theorem 1 if $C$ is closed under the addition of a sequence of constants, so that if $\alpha=\left\{\alpha_{t}\right\}_{t=1}^{\infty} \in R^{\infty}$, and $\psi_{t}\left(y^{t}\right)-\psi_{t}^{\prime}\left(y^{t}\right)=\alpha_{t}$ for all $t, y^{t}$, then

$$
\psi \in C \Longrightarrow \psi^{\prime} \in C
$$

For example, the class $C$ may consist of the affine tax codes discussed by Werning (forthcoming). ${ }^{4}$

\section{Multiple Equilibria}

The equivalence described in Theorem 1 is limited in the following way. Suppose $c$ is an equilibrium consumption allocation in a public-money economy defined by $M^{p u b}$ and $\tau$. Then, Theorem 1 says that there is an outcome-equivalent equilibrium outcome in the private debt economy defined by $B^{\text {priv }}$. The theorem does not say that the sets of equilibrium outcomes are the same in the two economies.

The following example makes this point more forcefully.

Example 1. Suppose that $\Theta=\{1,2\}$, that $\theta_{t}=1$ for all $t$ with probability $1 / 2$, and that $\theta_{t}=2$ for all $t$ with probability $1 / 2$. Suppose that $u(c, y)=\ln (c)$, so that output is inelastically supplied and $\beta>1 / 2$. Finally, suppose that for all agents, $y_{t}=\theta_{1}$ if $t$ is odd and $y_{t}=3-\theta_{1}$ if $t$ is even.

Consider a public-money economy in which $M_{t}^{p u b}=1$ for all $t$. It is well-known that there are (at least) two equilibria in this economy. In the one equilibrium, $p_{t}=0$ for all $t$, and $c_{t}=y_{t}$ for all $t$. In the other equilibrium:

$$
p_{1}=(4 \beta-2) /(5+2 \beta)
$$

\footnotetext{
${ }^{4}$ To impose lump-sum taxes in the public-money economy, the government must be able to threaten agents with some kind of penalty if they fail to pay those taxes. Kocherlakota (2003) and Berentsen and Waller (2006) argue that these penalties could be used to enforce cross-agent transfers of resources, and thereby eliminate the need for money altogether. However, to ensure that there is no need for money, the government must be able to impose an arbitrarily large penalty, and know the realization of $\theta$ for each agent. Neither of these assumptions is implied by the government's being able to levy a particular lump-sum tax of size $\tau^{\text {mon }}$.
} 


$$
\begin{aligned}
& p_{t}=p^{*} \equiv(2 \beta-1) /(2+2 \beta), t>1 \\
& c_{1}(2)=2-p_{1} ; c_{1}(1)=1+p_{1} \\
& c_{2 t+1}(2)=c_{2 t}(1)=2-2 p^{*}, t=1,2,3, \ldots \\
& c_{2 t}(2)=c_{2 t+1}(1)=1+2 p^{*}, t=1,2,3 \ldots
\end{aligned}
$$

(Here, $c_{t}(y)$ is consumption in period $t$ if $y_{1}=y$.) In this latter equilibrium, the two agents swap the money stock back and forth in exchange for consumption.

As in Theorem 1, construct a private bond economy by setting

$$
B_{t}^{\text {priv }}=p_{t}, t>1
$$

for all $t$. There is an equilibrium in this economy of the form

$$
\begin{aligned}
& r_{1}=(1-2 \beta) /(4+4 \beta) \\
& r_{t}=0, t>1 \\
& c_{1}(2)=2-p_{1} ; c_{1}(1)=1+p_{1} \\
& c_{2 t+1}(2)=c_{2 t}(1)=2-2 p^{*}, t=1,2,3, . . \\
& c_{2 t}(2)=c_{2 t+1}(1)=1+2 p^{*}, t=1,2,3 \ldots
\end{aligned}
$$

This equilibrium is consumption-equivalent to the second equilibrium in the public-money economy. (In this equilibrium, the poor agents (with income 1) borrow as much as possible in each period.) However, in the private bond economy, there is no autarkic equilibrium. Hence, the set of equilibrium outcomes is not the same as in the original public-money economy.

\section{Welfare Implications}

Cole and Kocherlakota (2001) consider a setup in which agents have hidden endowments and store secretly over time. They prove that, under weak conditions, the symmetric Pareto optimum is the equilibrium outcome of risk-free borrowing and lending, subject to the natural borrowing constraint. The analysis in this paper shows that this symmetric Pareto optimum could also be implemented as an equilibrium in an economy in which agents can only hold money. Note that the rate of return on money in this economy is necessarily less than the rate of time preference. 
Aiyagari (1995) studies the properties of optimal capital income taxes in economies of this kind (in which agents trade only capital and risk-free bonds, and face shocks to their labor productivities). Aiyagari (1995) finds that the optimal capital income tax rate is positive, and the equilibrium interest rate in the economy is less than the rate of time preference. Using the logic of Theorem 1, one could redo Aiyagari's analysis in a public-money economy. Aiyagari's result implies that in such a setting, the optimal rate of return on money is less than the rate of time preference. ${ }^{5}$

\section{Conclusions}

In this paper, I make two key assumptions. First, I assume that the private and public sectors have the same collection powers. Second, I assume that money has no distinct transaction advantage over bonds. Under these two assumptions, I am able to establish an isomorphism across a broad class of one-asset incomplete markets economies.

In reality, the collection powers of the private and public sector may well differ, and money almost certainly does provide liquidity benefits that bonds do not. A great deal of attention has been given to modelling and understanding the latter phenomenon. In light of the theorem in this paper, the former issue seems an especially important one for understanding the impact of government financing decisions.

\section{References}

[1] Aiyagari, S. R., 1995. Optimal capital income taxation with incomplete markets, borrowing constraints, and constant discounting. Journal of Political Economy 103, 1158-1175.

[2] Aiyagari, S. R., McGrattan, E., 1998. The optimum quantity of debt. Journal of Monetary Economics 42, 447-469.

[3] Barro, R., 1974, Are government bonds net wealth? Journal of Political Economy 82, 1095-1117.

[4] Berentsen, A., Waller, C., 2006. The societal benefits of outside versus inside money. University of Notre Dame working paper.

\footnotetext{
${ }^{5}$ Aiyagari restricts attention to comparisons across steady states. Davila et al (2005) show that this restriction may lead to a misleading characterization of optimal taxes.
} 
[5] Cavalcanti, R., Wallace, N., 1999. A model of private bank note issue. Review of Economic Dynamics 2, 104-136.

[6] Cole, H., Kocherlakota, N., 2001. Efficient allocations with hidden income and hidden storage. Review of Economic Studies 68, 523-541.

[7] Davila, J., Hong, J., Krusell, P., Rios-Rull, V., 2005. Constrained efficiency in the neoclassical growth model with idiosyncratic shocks. University of Pennsylvania working paper.

[8] Green, E., Zhou, R., 2005, Money as a mechanism in a Bewley economy. International Economic Review 46, 351-371.

[9] Imrohoroglu, A., 1992. The welfare cost of inflation under imperfect insurance. Journal of Economic Dynamics and Control 16, 79-91.

[10] Kocherlakota, N., forthcoming. Injecting rational bubbles. Journal of Economic Theory.

[11] Kocherlakota, N., 2003. Societal benefits of illiquid bonds. Journal of Economic Theory 108, 179-193.

[12] Levine, D. K., 1991. Asset trading mechanisms and expansionary policy. Journal of Economic Theory 54, 148-164.

[13] Lucas, R. E., Jr., 1980. Equilibrium in a pure currency economy. Economic Inquiry 18, 203-220.

[14] Lucas, R. E., Jr., 1992. On efficiency and distribution. Economic Journal 102, 233-247.

[15] Shin, Y., 2006. Ramsey meets Bewley: Optimal government financing with incomplete markets. University of Wisconsin working paper.

[16] Taub, B., 1994. Currency and credit are equivalent mechanisms. International Economic Review 35, 921-956.

[17] Wallace, N., 1981. A Modigliani-Miller theorem for open market operations. American Economic Review 71, 267-284. 
[18] Werning, I., forthcoming, Optimal fiscal policy with redistribution. Quarterly Journal of Economics. 